\title{
Correspondence
}

\section{Citizens add to satellite forest maps}

Satellite data are invaluable for mapping India's remaining forests, but their coarse resolution limits the information they can provide for protection purposes (Nature 489, 14-15; 2012).

For example, individual tree species cannot be identified from satellite data. This encourages selective felling of valuable trees, such as teak, while green cover is maintained to avoid satellite detection. Also, remotely sensed data do not reveal areas where local communities have a close relationship with the forests, as in India's Meghalaya hills.

Mobilizing citizens to provide information on the ground ('crowd sourcing') complements remote-sensing data. Using devices such as mobile phones (see www. geo-wiki.org), this approach provides a means to report illegal logging, catalogue trees that need protection because of their cultural, ecological or economic importance, validate spatial forest data and quantify forest degradation. It also raises awareness and informs public debate on sustainable forest management. In Brazil, for example, citizens have used the Globo Amazônia website since September 2008 to log millions of complaints against illegal activities as a cause of deforestation (see www. globoamazonia.com).

The controversy over India's forest resources is worrying, but it points to an emerging transparency in governance that allows people's concerns to be voiced. Crowd sourcing would enhance this transparency while improving the quality of data.

Marijn van der Velde, Linda See, Steffen Fritz International Institute for Applied Systems Analysis (IIASA), Laxenburg, Austria.

velde@iiasa.ac.at

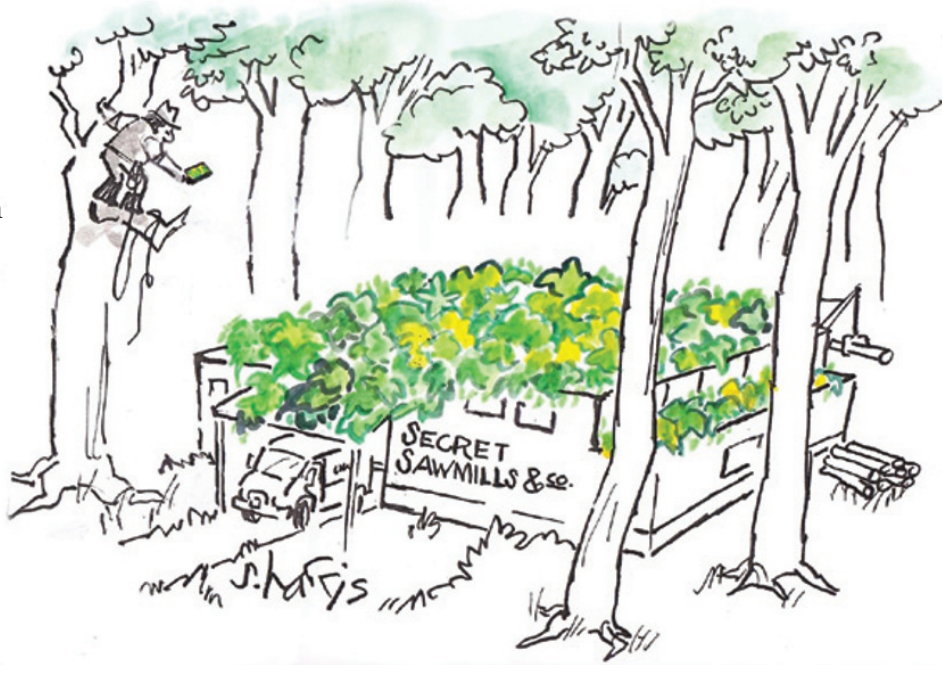

\section{Database for sharing costly equipment}

To mitigate the effects of the $45 \%$ government cuts to capital budgets in 2010, the UK Research Councils promoted the sharing of research equipment within and between institutions.

I published a report on this matter earlier this year for the N8 partnership of eight research-intensive universities in northern England (see go.nature.com/6jvpip), concluding that the overheads of sharing mean that it is mainly confined to expensive items, and that it works best when run within a collaboration. Already the study has catalysed strategic collaborations. Some researchintensive companies are also now exploring the possibility of joining these arrangements.

Logistical and cultural factors can be a problem. Most researchers will help friends and collaborators, but are wary of strangers using their facilities. They may worry about intellectual property or whether visitors will respect the equipment and are adequately trained in using it. It is easiest to set up sharing arrangements at the time of purchasing the equipment.

One challenge is to know what facilities are already available. Researchers might buy an item when there is one with spare capacity nearby. The N8 is developing standardized databases of capital assets built around a taxonomy of equipment types and functions. Availability will need to be checked because state-of-the-art items often operate at near-full capacity or may be configured to a particular experiment. Usage charges are also needed to cover access costs, such as technicians' time.

Luke Georghiou University of Manchester, UK.

luke.georghiou@manchester.ac.uk

\section{Cash puts publishing ethics at risk in China}

The number of scientific papers published in China in recent years has increased exponentially (see go.nature. com/8fjhdt). There are concerns that these numbers are being inflated by a payment scheme offered by some Chinese institutions to boost publication in journals with high impact factors (J. Shao and H. Shen Learned Publ. 24, 95-97; 2011).

Such monetary incentives could adversely affect scientific publishing behaviour in China. Payments to editors to improve the impact factor of their journal, for example, could encourage them to coerce authors into citing more articles from that journal (see go.nature.com/ye2gae). Or it could result in citation cartels in which journals cite each other for mutual benefit (see, for instance, go.nature.com/ p4u8on).

These schemes risk disrupting the drive to reduce ethical issues that undermine Chinese science. Sarah Huggett Elsevier, Oxford, UK.s.huggett@elsevier.com

\section{Rural factories won't fix Chinese pollution}

China's green movement is awakening and starting to receive global attention (see, for example, Q. Wang et al. Nature 489, 502; 2012). The municipal governments of Qidong and Shifang should be applauded for suspending two planned industrial plants likely to cause widespread pollution (Nature 488, 261-262; 2012). But there may be plans afoot to relocate these to rural areas.

Moving factories from cities to rural areas is becoming more common. The relocation by local government of a US\$1.4-billion paraxylene plant from Xiamen City in Fujian province to the less-developed Gulei Town was not welcomed by residents (T. Ma China Environ. Ser. 10, 33-49; 2008/2009). Their protests received little media attention or help from non-governmental organizations (NGOs), and the new plant is now almost complete.

Shifting pollution from urban to rural areas can only be a short-term fix. For example, rural and semi-rural factories trebled their contribution to the national wastewater discharge between 1990 and 2007 (see go.nature. com/kdgsh3; in Chinese), and there are more than 200 cancercluster villages in China where pollution is suspected as the major cause of death.

More local NGOs are needed 